\title{
ANALYSIS FRAMEWORK FOR TRANSLATION OF MARITIME LEGAL DOCUMENTS
}

\author{
Ma ISABEL DEL POZO TRIVIÑO \\ mdelpozo@uvigo.es \\ University of Vigo, Spain
}

\begin{abstract}
Maritime activity around the globe currently generates a great amount of translation work, especially from English into other languages. This paper focuses on the analysis of the translation process in maritime legal and administrative documents. The study first establishes which maritime documents are most often translated and a tool is then developed to analyse such documents in detail, based on the concept of textual genre. Such analysis would help translators to better understand these highly specialised documents and thus contribute towards improving translation of the same.
\end{abstract}

Key words: maritime documents, textual genre, subgenre, macrogenre, systems of genre.

\section{Introduction}

The sea is a medium that links people the world over. Maritime transportation around the globe nowadays accounts for huge turnover figures. This results in great commercial activity of a multicultural and multilingual nature, where most transactions are carried out in English. It is not surprising therefore that maritime activity generates a large amount of translation work, especially from English into other languages.

This paper focuses on the analysis of the translation process in maritime legal and administrative documents. Such documents shall be hereinafter referred to as maritime documents. Given the fact that legal translation is a very wide field wherein a lot of aspects are yet unexplored, I have chosen to concentrate on an area in which I have ample experience (+14 years) as a professional translator in Vigo (Spain) -a city with one of the most important commercial ports in Europe and in the world.

The principal objective of this paper is to first establish which maritime documents are most often translated and then develop a tool for analysing such documents in detail based on the concept of textual genre. The results of this paper would help translators to better understand these highly specialised documents and thus contribute towards improving translation of the same. Each and every genre is not analysed here ${ }^{1}$ due to space limitations and therefore only the genre analysis method, which facilitates translation from English into any other language, is presented herein.

\footnotetext{
${ }^{1}$ See Del Pozo (2007) for an extensive analysis of the most important maritime documents mentioned herein.
} 


\section{Principal maritime documents}

There are many documents linked to maritime activity which frequently need to be translated. These, according to their importance, include:

1. Sea Protest

2. Shipbuilding Contract

3. Bill of Lading

4. Protocol of Delivery \& Acceptance

5. Single Customs Declaration

6. Cargo Manifest

7. Vessel Purchase \& Sale Agreement

8. Maritime Insurance

9. Charterparty Agreement

10. Naval Mortgage

11. Privileged Maritime Lien

\section{The concept of genre applied to translation and its analysis framework}

The notion of genre began to gain impetus in Translation Studies after the 1970s and achieved wide acceptance through the work of Hatim \& Mason (1990), who followed audiovisual communication scholars such as Kress (1985) and systemic functionalist such as Martin (1984). They defined genre from an approach that includes formal, sociocultural and cognitive perspectives.

There are also many authors from the field of specialised translation who defend usefulness of classifying the several genres of a specialisation (García Izquierdo 2007, Monzó 2002). My opinion is that classification of texts into genres helps us to organise them prior to their actual analysis. Guidelines established by the research group GITRAD-GENTT have been used in this study to classify genres linked with maritime activity $^{2}$. The said research group has classified legal macro-genres and has also created an index card for legal genre analysis. GITRAD-GENTT guidelines have been used in this study as a starting point by adapting them for analysis of maritime documents. The said guidelines are flexible, dynamic and can be generally used for all types of legal texts.

The many advantages provided by genre taxonomy in two different systems (source $\&$ target) enable translators to benefit not only from a linguistic point of view but also from a sociocultural one. In this sense Borja states:

a comparison of several texts in their source and target languages is a task which is constantly performed by specialised translators. Translators need to master text typology in their field of specialisation in order to ensure that their translations

\footnotetext{
${ }^{2}$ http://www.gentt.es/
} 
contain the required textual, social and legal conventions ${ }^{3}$. There therefore arises a need to have schemes for classifying documents in each field of specialisation ${ }^{4}$ (1998).

Specialist translators greatly benefit from recourse to text taxonomy, both in source and target languages, since it helps them to understand and compare texts from organisational and contextual points of views. Mediators should always try to understand the characteristic traits of each text genre in order to adapt their translation to such characteristics so that any target user is able to identify the same ${ }^{5}$.

Paltridge (1994), on the subject of genre analysis, states that we should first determine our basis of analysis, i.e., whether we have taken into account just formal items or those of content as well. Text analysis was traditionally associated with form and not content, however, there is an increasing trend towards importance given to content:

(...) indicators of boundaries are most clearly seen in terms of content; that is, it is a cognitive rather than a linguistic sense that guides our perception of textual division (Paltridge, 1994: 295, apud Posteguillo, 1996).

Depending on the approach selected, analyses should essentially take into account both formal and content aspects, especially when the field of specialisation we are interested in is quite alien and unknown to most translators who for the very first time are faced with the task of converting text from one language into the other. If we are not familiar with the world of maritime law, then we would obviously not know the meaning of terms such as "Sea Protest" or how one writes a "Vessel Charterparty Agreement" or know which elements are essential to a "Bill of Lading" for it to have legal effect. Translators therefore should not only have a command of both source and target languages but also have extra-linguistic knowledge of the documents they intend to translate in order to be successful in their communicative mediation task.

The analysis framework proposed in this paper for studying the selected genres is a wide framework which takes into consideration not only formal and content factors but also linguistic and extra-linguistic ones.

\section{Analysis framework based on the genre concept}

The analysis framework proposed hereunder is deliberately eclectic since it contains concepts not only from Systemic Functional Linguistics but also from genre theory applied to translation studies.

${ }^{3}$ One of the useful and interesting trends of translation theory for this study was contrastive textology by Hartmann (1980).

${ }^{4} \mathrm{~A}$ lot of work has been done in the languages field to achieve specific objectives and there are many works on text classification, especially for economy and business, as well as for technical and scientific texts (Tannen, 1982; Biber, 1989, 1994; Swales 1990.

${ }^{5}$ Biber (1989) defends a similar argument and proposes the use of a (text-type) to refer to those texts that have maximum similarity with respect to their lexical characteristics (identified via statistical analysis). 
Concepts explained later in this article and which form the skeleton for the analysis framework are: macrogenre, genre, subgenre, communicative situation, formal and contrastive issues and relationship with other genres. The following table presents the basic structure of the analysis index card, which is based on GENTT guidelines for analysing specialisation genres:

\begin{tabular}{|l|}
\hline ANALYSIS INDEX CARD \\
Macrogenre \\
Genre \\
Subgenres \\
Communicative situation \\
Formal and contrastive issues \\
Relationship with other genres \\
\hline
\end{tabular}

Table 1: Analysis index card for specialisation genres

Concepts outlined in the analysis index card will be discussed in detail in the following paragraph.

\subsection{Macrogenre}

The macrogenre concept is a label that does not correspond with any "reality" and is therefore only valid for classification and taxonomic purposes. The following are the "labels" used for classifying genres linked to maritime activity.

The Administrative texts macrogenre includes texts from public administrations, (except court texts which are included under another macrogenre called "court texts"). This macrogenre is really quite extensive since there is an infinite number of genres related to public administrations that often need to be translated. Thus birth certificates, death or marriage certificates, police clearance certificates, academic certifications, vessel registry certificates, etc. are a few examples of the same.

Meeting of minds or mutual agreement is an agreement between one or more persons through which one or more persons are obliged to either do something or not to do it. Amongst "mutual agreements" we could highlight contracts, treaties, conventions, etc. This is also an extensive macrogenre which contains a huge number of genres.

Unilateral declarations. Texts of this type correspond to manifestations made by just one party. However, this is also a wide and flexible category since it contains many genres, which in turn fit into other macrogenres. For example, an expert's report is a "unilateral declaration" but it could also be a "Notarial Document". Testaments, powers of attorney, etc. can also be included under unilateral declarations or under Notarial documents. 


\subsection{Genre}

As explained at section 3, the genre concept associated with the multicultural nature of translation has been used in Translation Studies since the 1970s. The genre concept used in the present work includes formal and sociocultural aspects of texts. It also includes cognitive aspects, amongst which worth mentioning is the intention of participants in the communication action. Ezpeleta defines genre as follows:

Genres are firstly defined by the communication purpose that they try to fulfil. This is what determines the remainder of the characteristics and the one that permits differentiation between genres (2008:431).

At this level of analysis the function of the different genres that fit into the macrogenres mentioned in the earlier section is be described. It is important to clarify at this stage that the classification of genres sometimes coincides in the two systems (source and target) but no perfect equivalence in both systems is sometimes observed.

\subsection{Subgenre}

Certain genres in turn present specific manifestations that convert them into subgenres, since they respond to variations or specifications for the communication purpose (Ezpeleta, 2008). The said communication purpose variations or specifications can in turn be related to the end result or the communication action of the participants.

As in the case of genres, subgenres within a specific legal context may sometimes not coincide with the subgenres of a foreign legal system. In our field of interest, this mainly happens with genres that are less standardised and less uniform. This is because such genres and subgenres are included in the source language legal system but are not included in the international legal system, which is common to all countries.

For instance, the subgenres of Naval Mortgage are quite different in the different legal systems because the said document has not undergone a strong standardisation process. However, the subgenres of Charter Party are practically the same everywhere since they are always derived from the international model.

\subsection{Communicative situation}

We can only talk about genre when members of professional or academic bodies accept the same as one. Therefore, in order to explain the communicative situation of a specific genre, we must at times have recourse to Linguistic concepts. These refer to the register (field, tenor and mode) and to the user (transmitter, receiver, idiolects, etc.) (Gamero 2001: 55). We shall now analyse the tenor in which documents of interest to us, are written. Tenor in our case is formal since the documents are legal and administrative ones. The field is specialised because we are talking about maritime documents and these documents are drafted by specialists, therefore their mode will always be written.

However, as mentioned earlier, my conception of translation activity is framed within a global analysis which takes into account not only the document's field of 
specialisation, tenor and mode of presentation but also that such activity is carried out within a specific sociocultural context which strongly affects the nature of the same. Therefore, when we approach a text, we ought to also analyse the sociocultural context in which each of the genres analysed fit in. Along the same lines, Gamero outlines factors that must be taken into account when considering the "communicative situation" of a specific genre and therefore its sociocultural context:

With respect to translation, one should bear in mind that sociocultural contexts: (a) determine genre conventions in each culture, (b) perform a primordial function when creating new genres since they respond to specific communication needs which may be common or not in the different cultures, and (c) determine the guidelines in genre evolution since they adapt to changes produced in the culture, in which they are used (2001: 57).

\subsection{Formal and contrastive issues}

Genres are structured and conventionalised communication actions. Cuddon describes convention as:

...a device, principle, procedure or form which is generally accepted and through which there is an agreement between the writer and his readers which subjects him to various freedoms and restrictions (1992: 192).

Conventions that characterise genres are the formal traits sanctioned by the user community to the detriment of other linguistically acceptable ones but which do not fit into the agreed patterns (Ezpeleta 2008: 432). Formal aspects refer to directly observable elements of the communicative fact, namely; structural characteristics and intra-textual aspects (amongst which are level of discourse, lexicon, level of terminological density, non-verbal graphical elements, etc.).

This section therefore analyses issues of a formal nature that characterise a specific genre and can be divided into:

(a) Macro-structure related issues, such as document size, its spread into paragraphs, clauses, etc; and

(b) Micro-structure related ones, such as syntax, aspects related to cohesion and coherence, typography, terminology and phraseology, etc.

Macro-structure. It is not uncommon to find that genres present a macro-structure which changes according to the cultural context in which they arise. Likewise, it would not be surprising to find a uniform format in certain genres that is independent of the cultural context in which they fit in. For documents generated within maritime activity, there is a strong trend towards homogenisation of documentation and therefore macrostructure of such documents tends to be quite similar if not identical.

Translation is a discipline that always involves a minimum of two languages and therefore in order to know the elements contained in each of them, it is sometimes quite useful to be able to compare genre macro-structure in the two languages. Such comparative analysis acquires higher relevance in genres whose macro-structures differ greatly in the two systems. Relevance is low when genres are practically the same in both systems. 
We are faced with a dilemma during translation when macro-structures are different in both target and source languages. The translator is thus faced with the eternal dilemma of whether to adapt the text or not. The following are the options available:

- Respect the macro-structure of the source text and reproduce it in the target text.

- Adapt macro-structure of the original text to the generic macro-structure of the target text.

- Adopt an intermediate solution which results in a hybrid.

The third possibility leads us directly to the concept of "transgenre", which was coined by Monzó in 2001 and further developed in her doctoral thesis in 2002. The author understands a transgenre as follows:

a genre that is exclusive to translation and includes the three cultural, cognitive and discursive aspects of genre; it shares characteristics that are homogeneous among texts belonging to the same genre and displays differences with respect to the original texts in the source and target cultures which it could be considered as being analogous to (Monzó, 2001: 251).

A transgenre arises when a genre belonging to a specific sociocultural and linguistic context gets transferred to a new sociocultural and linguistic context. The translational process creates a sole hybrid with unique characteristics that contains elements from the source context para-culture as well as elements from the target context para-culture.

Microstructure. On the subject of micro-structural issues, we can highlight analysis of language related aspects, syntax, phraseology, terminology, etc., which characterise a specific text genre.

In case of legal genres, most formal issues are determined by the legal context in which they are inserted and therefore by the legal system governing the same. Thus, legislative aspects that affect each of the genres in the respective legal systems should also be included at this analysis level which is dedicated to formal and contrastive issues.

\subsection{Relationship with other genres}

This is where inter-relationship between genres is analysed and a brief review of Bazerman's work would help here. The author states that from a legal point of view, there exist what he calls "systems of genre" which the author describes as "...interrelated genres that interact with each other in specific settings"6 (1994: 97). Bazerman states that a good amount of genres are interdependent and cites the example of patents:

Only a limited range of genres may appropriately follow upon another in particular settings, because the success conditions of the actions of each require various states of affairs to exist. That is a patent may not be issued unless there is an application. An infringement complaint cannot be filed unless there is a valid patent. An affidavit about the events in a laboratory on a certain date will not be sworn unless a challenge to the patent is filed (1994: 98).

\footnotetext{
${ }^{6}$ Yates and Orlikowski (2002) developed the genre system concept in a paper titled: "Genre systems: Structuring interaction through communicative norms". Also see Bazerman (2003) and Russell and Yáñez (2003).
} 
There is a clear "genre system" within documents that are generated as part of maritime activity. This system in turn has a number of sub-systems. In fact law firms have created their own genre systems and often request translation of all inter-related documents (genres that are linked within a specific project). Purchase \& Sale Agreement of a new vessel can be cited as an example in this case. Such an operation cannot be carried out without reference being made to the Shipbuilding Contract which governs construction of the vessel. The buyer of the vessel must provide approval to the construction of the vessel by the shipyard prior to signing the Vessel Purchase \& Sale Agreement. In like manner, and at the time of purchase, the shipyard must provide documents related to the seaworthiness of the vessel built, together with registration documents, etc. Other documents issued at the time of purchase are Bill of Sale and Protocol of Delivery and Acceptance. All of the above are part of the one transaction that requires a well defined documentary system or what Bazerman calls "systems of genre".

We have so far established the different strategies or levels that can be taken into consideration when carrying out the analysis of legal documents for translation purposes. The following sections describe the designed analysis framework proposal and its application to classification and study of the most important maritime documents. In the present work we have only considered the classification of documents into macrogenres, genres and sub-genres, however, the remaining levels of analysis will be incorporated into future research works.

\section{Proposal for classifying the principal maritime genres}

The following is a classification proposal for maritime genres and subgenres that are grouped under a wider macrogenre. Justification for the proposal is also provided hereunder.

\begin{tabular}{|lc|}
\hline \multicolumn{2}{|l|}{ Administrative } \\
\hline - & SINGLE CUSTOMS DECLARATION \\
\hline Meeting of minds/mutual agreements \\
\hline - & SHIP MORTGAGE \\
- & SHIPBUILDING CONTRACT (SBC) \\
- & SALE CONTRACT \\
- & CHARTER PARTY \\
& $\circ \quad$ TIME CHARTER \\
& VOYAGE CHARTER \\
O $\quad$ DEMISE/BAREBOAT CHARTER \\
MARITIME INSURANCE \\
$\circ \quad$ HULL INSURANCE \\
O CARGO INSURANCE \\
O P\&I INSURANCE \\
PRIVILEGED MARITIME LIENS \\
\hline
\end{tabular}




\begin{tabular}{|ll|}
\hline \multicolumn{2}{|c|}{ Unilateral declarations } \\
\hline - & BILL OF LADING \\
- & SEA PROTEST/NOTE OF PROTEST \\
\hline
\end{tabular}

Table 3: Proposal for classifying the principal maritime genres

The proposal put forward for genre classification is not a closed one. It is an information classification system which has proved to be of much value to me in organising information for the purpose of this study.

For further illustration, we can state that contracts (including the Shipbuilding Contract) are "meeting of minds", while a Bill of Lading, for example, would be a "unilateral declaration" since it is a document drafted by the Captain of a vessel to certify goods carried onboard the vessel. However, as stated above, the multifunctional nature of certain documents warrants their simultaneous inclusion in several macro-genre categories. Therefore, in the mentioned case of Bill of Lading, we can say that it is a "unilateral declaration" and also an "administrative document" since it is a requisite required by Public Administrations for certain procedures.

\subsection{Justification for classification proposal}

The following is the justification for classifying frequently translated maritime texts into macro-genres, genres and subgenres.

\subsubsection{Macrogenre: Administrative}

Single Administrative Document (SAD). This is an "administrative document" and it is the main customs declaration used in international trade. Traders and agents use this document to declare imports, exports, and transit \& community status declarations. It is also used to deposit and remove goods from customs warehouses. The SAD is aimed at ensuring openness in national administrative requirements, rationalize and reduce administrative documentation, reduce the amount of requested information and standardize and harmonize data ${ }^{7}$. Our research did not find presence of any subgenres for this genre, since it is a standardised international document.

\subsubsection{Macrogenre: Meeting of minds}

Ship Mortgage. This is a mutual agreement through which a mortgagor mortgages a vessel in favour of a mortgagee in exchange for a sum of money.

In as far as principal sub-genres of Naval Mortgage are concerned, mention must be made of the U.K.'s Deed of Covenant.

\footnotetext{
${ }^{7}$ http://ec.europa.eu/taxation_customs/customs/procedural_aspects/general/sad/index_en.htm
} 
Shipbuilding Contract (SBC). This is a "meeting of minds" (mutual agreement) entered into by the parties by which the ship-owner entrusts construction of a vessel to a shipyard which undertakes such construction.

As stated earlier, variations or specifications of the communicative purpose of genres give rise to subgenres. Such variations or specifications of the communicative purpose can in turn be related to the field of use, to its purpose, or to the participants in the communication action. The absence of any typical legal regulation both in Spanish and Anglo-American legal systems together with the trend towards international unification of norms that govern maritime law mean that standard forms are increasingly being used at the international level. This study considers such forms as subgenres within the SBC genre since they present variations that are related to scope of use, final objective, or the participants in the communication action. At times, choice of form will be based on influence of trade association which the builders belong to. Amongst the most widely used SBC types, special mention must be made, according to Gabaldón y Ruiz (2002: 253): of

a) The Shipbuilding Contract of West European Shipbuilders, (AWES). It revised and reissued in May 1999.

b) Shipbuilding Contract of the Maritime Subsidy Board of the United States Department of Commerce Maritime Administration (MARAD Form). It is used in relation to American newbuildings financed under Federal Ship Financing Program and authorized by Title XI of the Merchant Marine Act 1936.

c) Shipbuilding Contract of the Ship-owners Association of Japan (SAJ Form), It was published by the Shipbuilders' Association of Japan in January 1974 and the framework of this form is commonly used in South Korea, China, Singapore and Taiwan.

d) Norwegian Standard Form Newbuilding Contract (NSF), drafted as a result of negotiations between Norwegian ship-owners associations and shipbuilders.

Ship Purchase \& Sale Agreement. This is a mutual agreement. It is a legal agreement through which the seller transfers ownership of the vessel to the buyer for a set consideration/price.

Amongst the many ship purchase and sale agreements considered within this section as subgenres (since they have special characteristics), we can highlight some models of Ship Sale Contracts such as NIPPONSALE $/ 77^{8}$ and the SALESCRAP, the latter being designed for vessel scrapping.

Mention must also be made at this point of a practice at the time called sale "according to good or bad news". This was used whenever communication with the vessel was not possible (when current day communication systems were unavailable). It was a random agreement wherein the buyer risked paying the price of a vessel despite the fact that the vessel could be lost.

Charter Party. According to Alcaraz \& Hughes (1997: 78), the term charter party is derived from the Latin term "charta partita". It was so called because the agreement was divided into two parts upon signature and each party kept one part. The charter party is an agreement wherein the vessel owner places his vessel at the disposal of the charterer so that goods can be shipped in exchange for payment of freight.

\footnotetext{
${ }^{8}$ http://www.bimco.dk/Corporate\%20Area/idea/News/NIPPONSALE\%201999.aspx
} 
Many subgenres can be found within the genre Charterparty and these require a detailed explanation due to the importance of such documents for maritime goods transportation. The following are the most important Charterparty agreements:

Time-Charter. This is an agreement which places a vessel at the disposal of a Charterer for a fee, so that the Charterer can undertake the voyages needed during a certain time period. Del Pozo \& Padín state the following on the same:

This agreement transfers commercial management of the vessel to the Charterer, wherein the ship-owner company retains control and seafaring management of the vessel. The characteristic of this agreement is that expenses and risks are shared between the parties: the ship-owner company pays for vessel navigation expenses while the Charterer takes on commercial exploitation expenses and risks. This agreement is quite often used in practice (2005: 809).

The lack of specific legislation about the form of this agreement has given rise to a number of Time-Charter models amongst which mention must be made of: BALTIME, NYPE, LINERTIME charterparties and models created by oil companies such as STBTIME, SHELLTIME 4, etc. .

Voyage-Charter. Del Pozo \& Padín state (op. cit.: 810) that it is a "typically historical contract" which is entered into when the charterer contracts the entire load capacity of a vessel on a certain voyage. The authors further state:

...no management, commercial or seafaring transfer of vessel takes place, i.e.; the ship-owner company has full control of the same and only just places vessel transportation capacity at the disposal of the charterer for a specific trip (op. cit.: 810811).

Several types of agreements are used for Voyage-Charters and include GENCON, the most used Charterparty model. Other Voyage-Charter models are CORE 7, EXXONVOY and SHELLVOY.

The authors state that there is a substantial difference between Time-Charter and Voyage-Charter:

... commercial management of vessel is transferred from vessel owner to charterer in Time-Charter, while in Voyage-Charter such management is retained by vessel owner. The basic characteristic of Time-Charter is the subordination of the Captain to the Charterer in so far as voyages to be undertaken is concerned (op. cit: 811).

Demise/Bareboat Charter. As explained by Alcaraz \& Hughes (1997: 79), here, the vessel owner rents the vessel to the charterer without crew or fuel, and the charterer assumes all expenses and responsibility during the validity period of the agreement.

Others. Besides the abovementioned three types, there are other types of contracts which are half-way between Time-Charter and Voyage-Charter. These include:

\footnotetext{
${ }^{9}$ Buelga \& Wilson (1994) provide a classification of Charterparties in line with the purpose of transportation.
} 
> Consecutive Voyage Charter, in which the vessel is chartered for a set of continuous voyages or for a fixed amount of voyages that can be undertaken during a certain time period.

$>$ Volume Contract or Tonnage Agreement, wherein a vessel is chartered for as many trips as are needed to transport a specific amount of goods.

$>$ Round Trip Charter, where the vessel is chartered for one trip but based on a Time-Charter, i.e.; the vessel is chartered for the time taken by a specific trip.

$>$ Slot Charter, this type does not refer to the entire vessel but to a certain amount of slots, which are equally dimensioned spaces that occupy dimensions of a standard sized container.

Maritime Insurance. Marine underwriters, through Maritime Insurance, undertake to insure policy holders under certain circumstances, upon payment of a fee premium. The principal Maritime Insurance sub-genres include:

a) Hull Insurance, which covers vessel owner's interest in relation to a specific vessel. This insurance policy is of two types:

- Vessel Insurance, which includes hull, machinery, rigging and everything that belongs to a ship, including provisions and fuel.

- Liabilities Insurance, which covers material damage caused to third party goods.

b) Cargo Insurance, which insures goods loaded on a vessel for transportation, as well as any interests pertaining to the same. The ILU - Institute of London Underwriters published some clauses for Cargo Insurance called Institute Cargo Clauses ${ }^{10}$. It is the most frequently used type of document. ${ }^{11}$

c) Other Maritime Insurance Policies worth mentioning are Ship-owner's Freight \& Civil Liability, and P\&I Insurance. The history of P\&I Clubs is quite interesting and dates back to the $18^{\text {th }}$ century. They were established by vessel owners from different geographic areas who were not satisfied with cost and cover provided by insurance companies of the time. Although it is true that P\&I Clubs originated in Great Britain, they soon became international. Many insurance companies tend to follow the Anglo-Saxon insurance policy model and therefore P\&I Clubs have gained worldwide importance within the field of international maritime law. This has led to the need for translation from English into other languages.

Maritime Lien. This is a voluntary agreement whereby a creditor agrees to loan money to a debtor for carrying out navigation related activities.

Gabaldón \& Ruiz (2002: 268) and Arroyo (2002: 125), amongst other authors, indicate that Maritime Lien is one of the remarkable "characteristics" of Maritime Law because a creditor avails of the vessel to provide credit, something that does not happen with other credits regulated by civil or mercantile common law.

\footnotetext{
${ }^{10}$ Orts (2006) carried out a detailed study of these clauses.

11 The following link can be used to freely download all model policies pertaining to this organisation:

http://www.jus.uio.no/lm/private.international.commercial.law/insurance.html
} 


\subsubsection{Macrogenre: Unilateral declarations}

Bill of Lading $(\mathbf{B} / \mathbf{L})$. This is a "unilateral declaration" since the person-in-charge (captain, shipping agent or transport company) acknowledges receipt of goods onboard the vessel for transportation and undertakes to deliver goods to the legitimate holder of the title at destination. However, just like in the case of other documents, one can argue that this is an "administrative document" because at times the document is a requisite without which certain commercial transactions cannot be carried out.

There are many subgenres within the genre Bill of Lading. According to Gabaldón \& Ruiz (2002), and Del Pozo \& Padín (2005: 811), we can divide them into two main types ${ }^{12:}$

(a) Tramp Bills of Lading. These are issued for Voyage Charterparties and therefore most of their clauses are taken from the said charterparties through an incorporation mechanism. They are mainly used for bulk carriage. Del Pozo \& Padín highlight CONGENBILL13 (bill of lading to be used with charter-parties) and INTANKBILL 78, used mainly for transportation of crude oil.

(b) Liner Bills of Lading. These are autonomous Bills of Lading which specify carriage conditions since they are conceived for vessels that serve on regular routes. The CONLINEBILL is worth mentioning here, which specifies that it is a Liner Bill of Lading.

Sea Protest/Note of Protest. A Sea Protest is a "unilateral declaration" because it is generally made by the person commanding the vessel and is made to cover the interested party from any possible liability that may arise. There is no intervention from any other party. During our study, we did not find any evidence of subgenres for the genre Sea Protest.

Cargo Manifest. This is a "unilateral declaration" because it is a document drafted by the Captain after goods have been loaded onto the vessel. However, just like in the case of Bill of Lading, we can also argue that this too could be considered as an "administrative document" for the same reasons explained hereinabove.

There are two subgenres for the Cargo Manifest, namely:

a) Inward Manifest: a document that needs to be handed upon arrival of vessel at a port.

b) Outward Manifest: a document that needs to be handed over at departure of vessel from a port.

Now that justification has been provided for classification into genres and subgenres, I would like to clarify that this is not a final or rigid proposal since we could debate that the analysed genre could possibly be included under other macrogenres. Therefore, we may argue that a Bill of Lading could be considered as a "unilateral agreement" and thus could also be included under the "administrative document" macrogenre. This proposal is therefore dynamic and flexible, where the objective is to contribute to organising the different textual genres that are connected with maritime activity.

${ }^{12}$ Buelga \& Wilson (1994) provide an exhaustive presentation of the several Bills of Lading. Socorro (2002) presents a list of the principal Bills of Lading approved by BIMCO. 


\section{Conclusions}

Several conclusions can be drawn from this study, some of them already mentioned in earlier paragraphs. Firstly, we can conclude that there is a field of specialization within translation, namely; translation of documents related to maritime activity. These documents contain special characteristics that translators ought to know, in order to successfully carry out their linguistic mediation task. Such characteristics may at times be purely formal or linguistic, while at other times they may be influenced by extratextual conditions, such as the legal system of the country where the original documents were written. Therefore, translators need to have an in-depth knowledge of the genres they translate such that their translation fulfils the same communication purpose in the target language as in the source language text.

Secondly, we can also conclude that there are certain textual genres that are translated more often than other genres. This conclusion helps us to decide which genres should be analysed in detail, in order to obtain a greater yield from our analysis. Therefore, we can conclude that the three most "yielding" genres for analysis are: Sea Protest, Shipbuilding Contract and Bill of Lading 14 .

The third conclusion that can be drawn is the predominance of English in international relations, and more precisely within maritime activity, and therefore its designation as a vehicular language by the IMO (López \& González 2004). Most documentation related to maritime activity is drafted in English even though place of origin of the document may not be an English speaking country. It is normal that such English originals are sent for translation into target languages although there are times when originals written in other languages need to be translated into English. An example of the latter is Naval Mortgage, which is signed by companies of a certain country with partners from a foreign country.

The present work has presented classification of the most frequently translated maritime documents into macrogenres. Such classification is followed by an analysis index card that helps one to undertake a detailed study of maritime genres. Further work will hopefully permit us to apply the analysis framework presented here, in order to throw more light on this specific section of translation studies.

\section{References}

Alcaraz, E. \& Hughes, B. 1997. Diccionario de términos jurídicos. Inglés-español. Barcelona: Ariel.

Arroyo, I. 2002. Compendio de Derecho Maritimo. Madrid: Tecnos.

Bazerman, Ch. 1994. "Systems of genres and the enactment of social intentions" in Genre and the New Rhetoric de Freedman A. \& P. Medway eds., 79-101. London: Taylor \& Francis Ltd.

\footnotetext{
${ }^{14}$ See Del Pozo (2007) and Del Pozo \& Padín (2005).
} 
Bazerman, Ch. 2003. "What is not institutionally visible does not count: the problem of making activity assessable, accountable, and plannable" in Writing selves/writing Societies: Research from Activity Perspectives by Bazerman, Ch. \& D. Russell, eds.. http://wac.colostate.edu/books/selves_societies/ [Last visit: 14.07.07].

Biber, D. 1989. "A typology of English texts" in Linguistics 27, 3-43. DOI: 10.1515/ling.1989.27.1.3, //1989

Biber, D. 1994. "Towards a comprehensive analytical framework for register studies" en Perspectives on Register: Situating Register Variation within Sociolinguistics by Biber, D. \& E. Finegan, eds. Oxford University Press, 235-276.

Borja, A. 1998. Estudio descriptivo de la traducción jurídica. Un enfoque discursivo. $\mathrm{PhD}$ thesis. Universitat Autònoma de Barcelona, Department of Translation \& Interpretation.

Buelga, J. \& D. Wilson 1994. English for Maritime Commerce. Colegio de Oficiales de la Marina Mercante española. Madrid: Iberediciones.

Cuddon, J. 1992. The Penguin Dictionary of Literary Terms and Literary Theory. Harmondsworth: Penguin.

Del Pozo, M. 2007. Análisis contrastivo de los géneros del derecho maritimo para la traducción inglés-español. PhD thesis. CD Rom. University of Vigo Publications Service.

Del Pozo, M. \& Padín, A. 2005. "Conceptos básicos sobre los principales contratos de explotación de buques”. In Actas del II Congreso Internacional AIETI, 808-819. Madrid: Universidad Pontificia de Comillas. CD-Rom format.

European Commission Taxation and Customs Union. http://ec.europa.eu/taxation_customs/customs/procedural_aspects/general/sad/index_en .htm. [Last visit: 21.12.2010].

Ezpeleta, P. 2008. "El informe técnico. Estudio y definición del género textual". In La traducción del futuro: mediación lingüistica y cultural en el siglo XXI. Vol. II La traducción y su entorno, Luis Pegenaute, Janet DeCesaris, Mercè Tricás and Elisenda Bernal eds., 489-501. Barcelona: PPU.

Gabaldón, J.L. \& Ruiz, J. 2002. Manual de derecho de la navegación marítima. $2^{\mathrm{a}}$ ed.. Madrid: Marcial Pons. Ediciones Jurídicas y Sociales S.A.

Gamero, S. 2001. La traducción de textos técnicos. Descripción y análisis de textos alemán-español. Barcelona: Ariel.

García Izquierdo 2007. "Los géneros y las lenguas de especialidad". In Las lenguas profesionales y académicas by Alacaraz E. ed.. Alicante-Barcelona: Ariel. IULMA. Pp. 119-125.

Hatim, B. \& I. Mason 1990. Discourse and the Translator. London: Longman.

Hartmann, R. K. 1980. Contrastive Textology. Studies in Descriptive Linguistics. Heidelberg: Julius Groos Verlag.

Kress, 1985. Linguistic Processes in Sociocultural Practice. Victoria: Deakin University Press.

López, A. \& González, I 2004. Inglés maritimo. A Coruña: Netbiblo.

Martin, J.R. 1984. "Language, register and genre" by Christie F. ed.. Children Writing: Reader. Geelong: Deakin University Press. 21-29.

Monzó, E. 2001: El concepte de gènere discursiu. Una aplicació a la traducció jurídica. Research Project, Castelló, Universitat Jaume I. 
Monzó, E. 2002. La professió del traductor juridic i jurat: descripció sociologica del profesional $i$ anàlisi discursiva del transgènere. $\mathrm{PhD}$ thesis. Castellón: Universitat Jaume I.

Orts, M. 2006. Aproximación al discurso jurídico en inglés. Las pólizas de seguro maritimo de Lloyd's. Madrid: Edisofer.

Posteguillo, S. 1996. Genre Analysis in English for Computer Science. PhD Thesis collection. Valencia: University of Valencia.

Russell, D. \& A. Yáñez, 2003. "Big picture people rarely become historians': Genre systems and the contradictions of general education". In Writing Selves/Writing Societies: Research from Activity Perspectives by Bazerman C. \& D. Russell, eds.. http://wac.colostate.edu/books/selves_societies/ [Last visit: 14.04.09].

Socorro, K. 2002. La traducción comercial: un modelo didáctico para la traducción de documentos mercantiles del comercio internacional inglés-español. $\mathrm{PhD}$ thesis. University of Las Palmas de Gran Canaria.

Swales, J. 1990. Genre Analysis: English in Academic and Research Settings. Cambridge: Cambridge University Press.

Tannen, D. ed. 1982. Spoken and Written Language: Exploring Orality and Literacy. NJ: Ablex, Norwood.

Yates, J. \& W. Orlikowski 2002. "Genre systems: Structuring interaction through communicative norms". In Journal of Business Communication, 391, 13-3. 